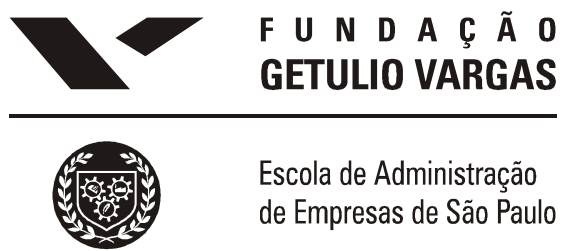

Este artigo foi traduzido e reproduzido com autorização de Academy of Management Executive, Review, Journal, or Learning and Education, periódicos de língua inglesa editados pela Academy of Management. Acesse www.aomonline.org para informações sobre Academy of Management ou assinaturas de suas publicações ou contate Susan Zaid, 235 Elm Road Briarcliff Manor, New York 10510, USA. szaid@pace.edu.

(C2003 Academy of Management. Todos os direitos são reservados. Nenhuma parte deste artigo pode ser reproduzida sem autorização escrita de Academy of Management. Obtenha autorização para reprodução e uso em sala de aula junto a Copyright Clearance Center (www.copyright.com).

\title{
GVexecutivo
}




\section{Desenvolvendo a criatividade dos grupos de traballho organizacionais}

criatividade vem se destacando cada vez mais como uma ca-
racterística imprescindível para equipes e indivíduos nos atu-
ais ambientes de trabalho das empresas. Este artigo discute as principais dificuldades e obstáculos ao desenvolvimento da criatividade nas equipes de trabalho. Ao mesmo tempo, propõe diversas estratégias para superar tais obstáculos e desenvolver as condições para que as equipes, em vez de dificultarem a criatividade individual, a estimulem.

por Leigh Thompson, Northwestern University

Criatividade - "como ignizá-la e como regenerá-la?" é a questão-chave que os gerentes e executivos colocam aos professores de administração e consultores. Diversas mudanças e desenvolvimentos organizacionais fazem da criatividade uma necessidade valiosa para a nova economia e para as organizações que a habitam. Primeiro, estruturas organizacionais mais horizontais requerem que empresas, divisões e gerentes ajam de uma maneira mais empreendedora einventiva. A ausência de hierarquia e burocracia cria uma oportunidade fértil para o pensamento e a ação criativos. Segundo, considerando-se os fatos, os negócios estão crescendo de modo cada vez mais competitivo. Estritamente 
falando, isso significa que as empresas vão precisar se reinventar continuamente. 0 livro de Frank e Cook, The winner-take-all society, oferece convincentes dados sobre como as empresas estão ficando mais competitivas, tornando-se "vencedoras" que ganham cada vez mais market share ${ }^{1}$. Terceiro, a confusão de fronteiras entre as noções tradicionais de quem está "dentro" e de quem está "fora" da empresa permite que as equipes formem novos relacionamentos com fornecedores, negócios complementares e shadow industries. Em Co-opetition, Brandenburger e Nalebuff argumentam que a cooperação e a competição podem co-existir nos relacionamentos de negócio². Finalmente, o foco no serviço ao cliente é mais importante do que nunca, e a busca da satisfação e do prazer do cliente exige criatividade.

Contudo, o fato deos desafios enfrentados por uma equipeexigirem criatividade não garantequeos membros da equipe serão criativos. Na verdade, diversos fatores que parecem incentivar a criatividade podem, na realidade, a ela se opor.

Realismo criativo. A maioria das pessoas pensa que as idéias criativas são caóticas; pelo contrário, a criatividade éa produção de idéias novas eúteis. A criatividade éimportante para a inovação. Se a criatividade pertence às idéias, então a inovação pertence aos serviços e produtos que se originam das idéias criativas. De acordo com um famoso psicólogo, James Guilford, o pensamento criativo ocorre quando um solucionador de problemas inventa uma nova solução para dado problema³. Idéias criativas e ações criativas são originais e valiosas. A Figura 1 mostra uma grade $2 \times 2$ definindo, em um continuum horizontal, idéias criativas e idéias conservadoras4. De acordo com o modelo, as equipes devem lutar para alcançar idéias criativas, que representam idéias altamente originais e novas enquanto algo oposto às idéias conservadoras e tradicionais.

O continuum vertical é muito freqüentemente desprezado. Ele distinguenovas idéias quesão realistas (conectadas às idéias e conhecimentos existentes) de idéias que são idealistas (desconectadas do pensamento existente). Se as novas idéias não forem conectadas às idéias e ao conhecimento existentes, el as são freqüentemente irrealizáveis.

0 melhor detodososmundos possíveis éconseguir idéias no quadrante esquerdo superior. Esse domínio é chamado de Realismo Criativo, pois essas idéias são altamente imaginativas e altamente conectadas às estruturas e idéias existentes. Já o Real ismo Conservador representa idéias que são altamentetradicionais e altamente conectadas ao conhecimento e às práticas existentes. Esse domínio contém pouca ambi-

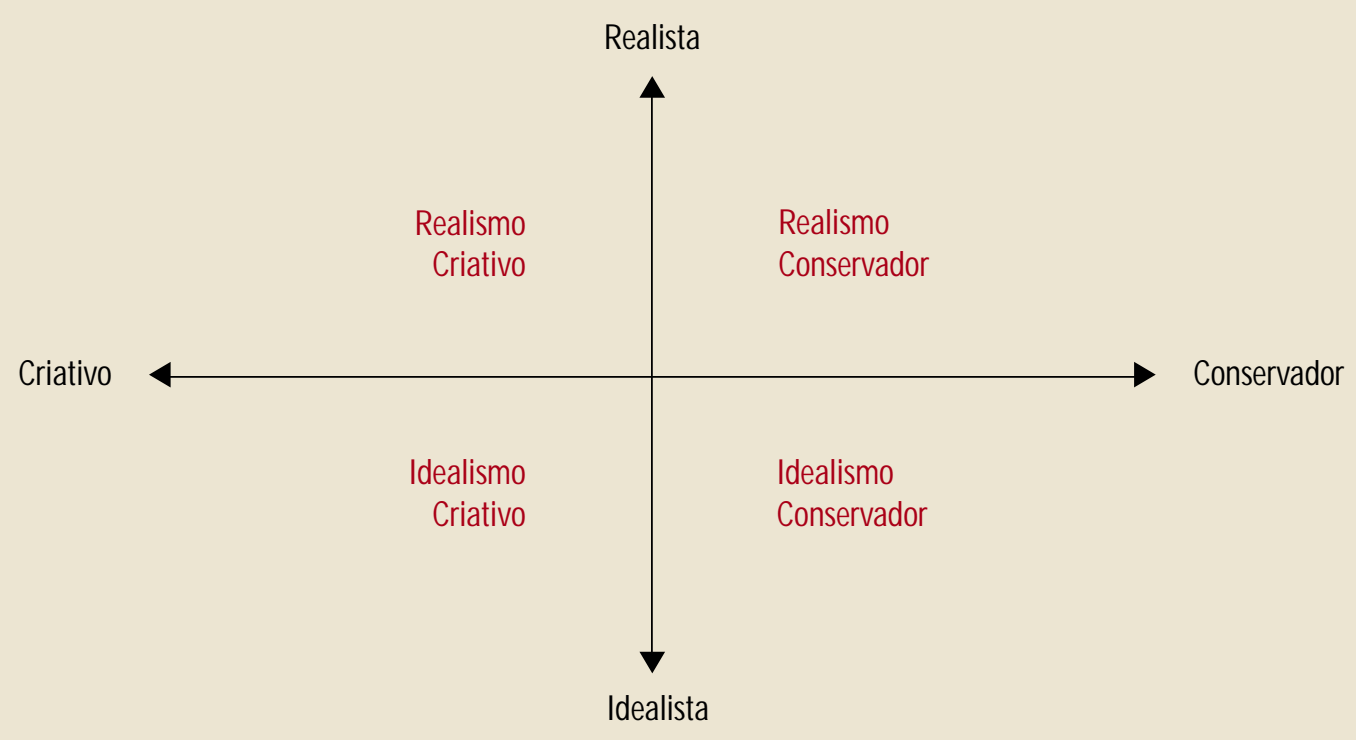

Figura 1: Quatro domínios gerais e conceituais em que as novas idéias podem ser classificadas

Fonte: Rinke, R. A. 1995. Creative realism. In S. M. Smith, T. B. Ward, \& R. A. Finke (Eds.), The creative cognition approach. Cambridge: MIT Press. $303-326$. 
güidade e pouca incerteza. 0 Idealismo Conservador é talvez o pior tipo de pensamento para uma empresa: a continuidade de uma idéia comum com a qual não é realista começar. Essas idéias apresentam pouca ou nenhuma imaginação e não estão conectadas ao pensamento existente. E 0 I dealismo Criativo representa idéias al tamente originais, embora al tamente não realistas.

A questão-chave é como as equipes podem maximizar a probabilidade de se fixarem no quadrante superior esquerdo (Realismo Criativo). As idéias que fluem desse tipo de pensamento são altamente originais e muito úteis. Um exemplo excelente de Realismo Criativo foi o desenvolvimento do sistema de iluminação elétrica por Thomas Alva Edison5. Depois que Edison inventou a luz incandescente, seu próximo projeto foi desenvolver um sistema inteiro, por meio do qual a invenção pôde se tornar comercialmente bem-sucedida. $\mathrm{Na}$ época, havia dois sistemas de iluminação em cena (nenhum desenvolvido por Edison): iluminação a gás e iluminação por arco voltaico. A primeira podia ser diretamente controlada pela luminosidade; o gás era produzido fora da cidade e enviado por meio de uma tubulação subterrânea. A iluminação por arco voltaico era produzida por uma faísca elétrica entre filamentos de carbono muito quentes que produziam uma emanação. A unidade de geração era instalada diretamente na casa do usuário. 0 sistema de iluminação de Edison era baseado nos princípios da iluminação a gás. Edson escreveu em seu diário de trabal ho queimitou completamenteo sistema a gás, substituindo o gás pela eletricidade. Em seu sistema elétrico, a fonte de energia ficava distante do usuário, e os cabos que transportavam a energia ficavam embaixo da terra. Além disso, as lâmpadas individuais eram ligadas e desligadas pelo usuário. 0 bulbo da lâmpada no sistema de Edison foi chamado de combustor e tinha a finalidade de produzir a mesma quantidade de luz que o combustor a gás.

Como veremos mais à frente, os esforços que as pessoas fazem para gerar idéias úteis no quadrante do Realismo Criativo às vezes não garantem que elas terminarão aí. Q uando o processo é iniciado, a rota é freqüentemente indireta e não óbvia.
Mensurando a criatividade. Em meus cursos deMBA e educação executiva, desafio os participantes a avaliarem sua própria criatividade usando uma medida-padrão de criatividade - o exercício da caixa de papelão de Guilford ${ }^{6}$. 0 procedimento é muito simples: cada participante gasta dez minutos escrevendo todos os usos que possa imaginar para uma caixa de papelão - o mesmo pode ser feito em relação a um tijolo etc. Sempre me surpreendo com a variedade de número, originalidade e qualidade das idéias da turma.

0 próximo passo é instruir os participantes para que avaliem a criatividade por meio desse exercício muito simples. Para fazer isso, introduzo o modelo trifatorial de criatividade de Guilford: fluência, flexibilidade e originalidade? .

"Fluência" é simplesmente uma medida do quanto uma pessoa consegue gerar de idéias diferentes. Como veremos adiante, Alex Osborn, o pai do brainstorming moderno, estava certo: a quantidade geralmente produz qualidade ${ }^{8}$. 0 intervalo típico que obtenho em minhas aulas de MBA e nos cursos de educação executiva é de 540 categorias de idéias.

\section{todas em uma quantidade pequena de tempo.}

"Flexibilidade" é uma medida do quanto uma pessoa produz de tipos diferentes de idéias. Por exemplo, imagine que uma pessoa que complete seu exercício, Sandy, produza três idéias: usando a caixa como jaula para um rato, como recipiente para colocar uma tartaruga, e uma casinha para o cachorro. Sandy receberia três pontos por fluência, pois há três diferentes idéias, mas somente um ponto por flexibilidade, pois as idéias são da mesma categoria - isto é, casas para animais. Demodo contrário, Pat sugere usar a caixa depapelão como um deus, um telefone (por meio de duas caixas e um barbante) e negociá-la como moeda de troca9. Pat receberia um escore de três pontos por fluência (o mesmo que Sandy), mas conseguiria três pontos por flexibilidade, pois 
há três categorias separadas de idéias - uma envolvendo religião, outra comunicação, e ainda uma terceira envolvendo zem os requisitos para uma conectividade estrutural, mas, como veremos, Pat e sua equipe estão em uma posição muito melhor para montar o cenário para o Realismo Criativo do queSandy. Pense na flexibilidade como um tipo de ginástica mental - a habilidade de considerar diferentes tipos de idéias, e todas em uma quantidade pequena de tempo. A maioria das pessoas e, em particular, a maioria das equipes tendem a ficar presas a um ou dois tipos de categorias de pensamento. Isso é um tipo de artrite cognitiva. 0 intervalo típico que obtenho em minhas aulas nos cursos de MBA e de educação executiva é de 4-17 categorias de idéias.

"O riginalidade" é uma medida da singularidade ou originalidade da idéia - isso é o que se quer significar por criatividade no continuum conservadorismo-criatividade na Q uadro 1. Estatisticamente, idéias originais são as quesão produzidas por menos de $5 \%$ de uma determinada amostra. Assim, em minhas investigações, se há 50 executivos em uma determinada aula, um ponto de originalidade é dado em relação a uma idéia somente se duas, ou menos, pessoas propuserem essa idéia particular. 0 intervalo típico que obtenho para os escores de originalidade em minhas aulas no MBA e nos cursos de formação executiva é de 0-14 categorias de idéias. economia. Claramente, al gumas das idéias dePat não satisfa-

quantidade não é valorizada e a qualidade é vista como o único objetivo mais importante. Se a flexibilidade é, de fato, o driver, como vamos montar o cenário para ela?

Pensamento convergente versus divergente. 0 pensamento convergente éo pensamento que avança em direção a uma única resposta. Por exemplo, considere o problema do jogo de azar: o VE, ou valor esperado, de uma chance de $70 \%$ de ganhar $R \$ 1$ mil é obtida mediante um algoritmo simples, tal que $\mathrm{R} \$ 1$ mil são multiplicados por 0.7 para se obter $R \$ 700$. Em contraste, o pensamento divergente move-se para fora de um problema, e o faz em muitas direções, além de envolver um pensamento sem fronteiras. 0 pensamento divergente é algo como o pensamento janusiano. 0 pensamento janusiano refere-se à divindade romana, Janus, que tinha duas faces olhando para direções opostas. Nesse contexto, o pensamento janusiano refere-seà habilidade de lidar com idéias conflitantes, paradoxos, ambigüidade e dúvida. Para estimular o pensamento janusiano, Tom Verberne sugere perguntar: "E se o mundo se transformasse em seu pior pesadelo ou em seu sonho mais lindo?"10. Q uestões que não têm limites estimulam o pensamento divergente. Depois que os participantes respondem a essas questões, conseguem identificar os fatores que influenciam os cenários em oposição. Esse tipo de pensamento pode impedir as pessoas de se jogarem na solução mais óbvia (e, freqüentemente, a mais cara). Verbene dá o exemplo dos hóspedes de hotel queixandose com o gerente pelo fato de terem de esperar muito tempo pelo elevador. 0 gerente reporta 0 problema para um engenheiro, que sugere instalar outro elevador. 0 gerente, não convencido pela cara solução, pede um conselho a um psicólogo. Este recomenda dar al guma coisa para as pessoas fazerem enquanto esperam - por exemplo, colo-

Há sempre uma surpreendente correlação entre as três medidas, tal que as pessoas que obtêm os escores mais al tos em originalidade obtêm também altos escores em flexibilidade e fluência. Desse modo, há uma forte associação entre quantidade, diversidadee novidade de idéias. De acordo com Guilford, a flexibilidade é um driver, o que depõe contra a maioria das noções business de criatividade, nas quais a diversidade de idéias freqüentemente não é recompensada, a cando espelhos e uma estante com revistas próximos aos elevadores. 0 gerente optou pela solução de menor custo e as queixas terminaram. Verbene também sugere trocas de papéis, por meio das quais os participantes questionam quais são as oportunidades ou os problemas que a empresa enfrenta, assumem os papéis uns dos outros na organização e questionam o que é importante a partir da perspectiva dos novos papéis que assumiram. 
As impossibilidades também podem estimular o pensamento divergente. Os participantes pensam em idéias que sejam impossíveis de executar (por exemplo, viver na lua, viajar em um satélite etc.) e então identificam as condições que poderiam levar à sua materialização.

Muitos dos fatores que caracterizam uma solução criativa de um problema estão relacionados com o pensamento divergente. A maioria das equipes requer algum pensamento convergente. No entanto, como veremos, as equipes tendem a focar o pensamento convergente às custas do pensamento divergente. Assim, surge um paradoxo: enquanto as equipes se destacam pelo pensamento convergente, 0 indivíduo se destaca pelo pensamento divergente. Isso é um paradoxo ao trabalho em equipe, pois, intuitivamente, a maioria das pessoas acredita fortemente que as equipes são mais criativas do que o indivíduo, quando, na verdade, elas não são.
Um amplo corpo de pesquisas em psicologia social e organizacional revela que, quando as equipes são contrapostas aos indivíduos, são as primeiras que se destacam por tarefas que requerem o pensamento convergente. Por exemplo, em um jogo de tomada de decisão clássico, onde há uma melhor solução predeterminada, grupos de pessoas produzem decisões superiores com uma freqüência maior do que fazem os indivíduos. Além disso, as instituições sociais e de negócios parecem saber disso e tiram proveito da situação. Presumivelmente, uma razão para se ter um júri com 12 pares é que o julgamento que daí resulta será mais equilibrado e exato do que se apenas uma pessoa ponderasse a evidência.

A tarefa mais difícil para a maioria das equipes é o pensamento divergente, ao qual as pessoas normal mente se referem como um "pensamento fora do padrão". Como uma observação geral, as idéias propostas por grupos e equipes

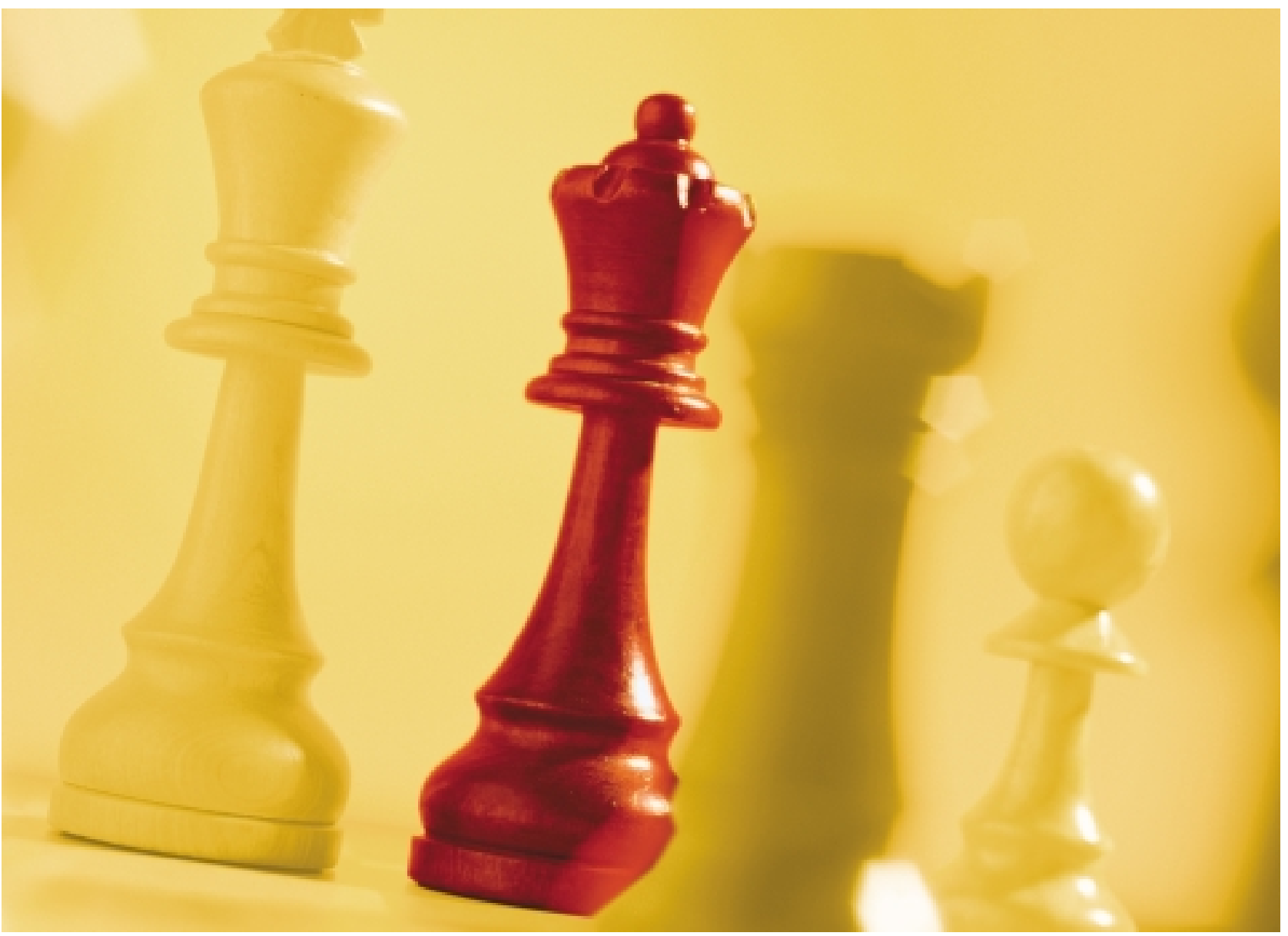


são mais clichês e tradicionais do que as idéias que os indivíduos, trabalhando sozinhos, criam. É como se as equipes agissem como um dispositivo normativo, aumentando assim a probabilidade de os membros do grupo se conformarem uns aos outros. Em diversas situações organizacionais, isso é altamente desejável, como quando as equipes desejam construir uma coesão e identidade. Contudo, a criatividade, por sua própria definição, requer diversidade de pensamento e de idéias. Marshall Fisher, co-fundador do Century 21 Real Estate, observou que, quando a maioria das pessoas são entregues a si mesmas, ela se envolve em um pensamento conformista e convergente. A idéia por detrás de seu programa, IdeaFisher, é que alternativas precisam ser deixadas livres. 0 programa IdeaFisher usa palavras-chave e frases e coloca-as em remissão recíproca com outras pal avras e frases semel hantes para reunir idéias diversas e diferentes que normalmente não vêm juntas de uma maneira al tamente organizada ${ }^{11}$. Diversidade também significa conflito, entre outras coisas; ea maioria das equipes deseja evitar o conflito a qualquer custo. Tal atitude pode lhe sair muito caro.

Brainstorming. Alex Osborn, um executivo do ramo da publicidade nos anos 1950, queria aumentar a criatividade das equipes nas organizações. Eleacreditavaqueum dos principais obstáculos à criatividade organizacional era a avaliação prematura de idéias. Ele estava convencido de que duas cabeças eram melhores do que uma para gerar idéias, mas somente se as pessoas pudessem ser educadas para não jul- gar suas próprias idéias e as de outras pessoas durante o processo de criação. Osborn desenvolveu então a mais disseminada prática executiva usada pelas empresas para encorajar o pensamento criativo: 0 brainstorming.

Em seu influente livro, Applied imagination, O sborn sugeriu que o brainstorming poderia aumentar de modo considerável a qualidadee quantidade das idéias produzidas pelos membros do grupo ${ }^{12}$. Além do mais, ele acreditava que 0 produto grupal poderia ser maior do que a soma das partes individuais se certas condições fossem satisfeitas. Portanto, desenvolveu regras para orientar a condução do brainstorming. De forma contrária à doutrina popular de que as sessões de brainstorming são descontrolas edesorganizadas, em quetudo é permitido, as regras de 0sborn eram específicas: (1) criticar é algo proibido; (2) rodadas livres são bem-vindas; (3) a quantidade é desejada; e (4) a combinação e o aprimoramento de idéias são encorajados (ver Quadro 1).

Osborn adequadamente percebeu quea quantidadeéum bom catal isador para a qual idade: uma equipe tem mais probabilidade de descobrir uma idéia real mente boa se tiver muitas idéias paraescolher. Porém, há muito mais no brainstorming do que a mera quantidade. Osborn acreditava que as idéias produzidas por uma pessoa em uma equipe poderiam estimular idéias em outras pessoas de uma forma sinérgica.

Muitas empresas ainda usam as regras originais de brainstorming sugeridas por Osborn 40 anos atrás. A empresa de design Ideo, do Vale do Silício, vive com base nessas regras. Douglas Dayton, da Ideo, diz que cinco regras orien-

\section{Quadro 1: Regras para o Brainstorming}

Expressividade: os membros do grupo devem expressar qualquer idéia que venha à mente, não importando se seja estranha, ou fantasiosa. Os membros do grupo são encorajados a não ficarem constrangidos ou tímidos. Devem se sentir o mais à vontade possível.

Não-avaliação: não criticar as idéias. Os membros do grupo não devem avaliar nenhuma das idéias e de nenhuma forma durante a fase de produção; todas as idéias devem ser consideradas válidas.

Quantidade: os membros do grupo devem produzir tantas idéias quanto possível. Os grupos devem se esforçar pela quantidade, como mais idéias, e melhores. A quantidade de idéias aumenta a probabilidade de encontrar soluções excelentes.

Construção: já que todas as idéias pertencem ao grupo, os membros devem tentar modificar e ampliar as idéias sugeridas pelos outros membros sempre que isto for possível. 
tam qualquer seção de brainstorming em sua empresa: "Ter uma conversa por um tempo. Construir sobre as idéias dos outros. Evitar fazer julgamento. Encorajar idéias descontroladas (não comportamento descontrolado). Permanecer focado no tema"13.

Osborn afirmou ter (mas não forneceu) evidências de pesquisas de que uma equipe que tenha adotado essas regras poderia gerar duas vezes mais idéias do que um número similar de indivíduos trabalhando sozinhos. Dessa forma, a comparação que ele tinha em mente era a de um grupo trabalhando face-a-face e um grupo-controle, conhecido na literatura como grupo nominal.

Isso funciona? Essa é a questão que os teóricos organizacionais fazem sobre a técnica de brainstorming. Q uase todos os estudos de laboratório revelaram que o grupo de brainstorming leva à produção de menos idéias do que um número comparável de membros individuais do brainstorming em contextos laboratoriais e organizacionais isto é, grupos nominais ${ }^{14}$. Assim, 40 ou mais anos de pesquisa sobre o brainstorming revelaram que ele é significativamente pior em termos de estímulo à criatividade quando comparado ao mesmo número de indivíduos trabalhando independentemente. De fato, virtualmente, todas as investigações empíricas de grupos de brainstorming são extremamente (não apenas moderadamente) negativas em relação à sua efetividade em comparação ao brainstorming individual. Como um exemplo típico, repare nas estatísticas apresentadas na Q uadro 2, que são dados de desempenho real de grupos de brainstorming e de indivíduos isolados em termos de quantidade e qualidade de idéias.
Com base nesses resultados, replicados diversas centenas de vezes com uma variedade de equipes fazendo brainstorming sobre todos os tipos de coisas, o mesmo padrão surge reiteradas vezes. De acordo com Muller et al., "parece particularmente difícil justificar as técnicas de brainstorming em relação a qualquer resultado de desempenho, e as técnicas de brainstorming, que já são populares há muito tempo, são inequívoca e substancialmente mal orientadas" ${ }^{\prime 15}$.

Contudo, as empresas que usam tal recurso não parecem dar ouvidos a isso. A despeito da evidência empírica sobre sua ineficiência, o brainstorming de grupo continua popular nos negócios ${ }^{16}$.

Maiores ameaças à criatividade da equipe. Há quatro principais problemas que servem para abafar a efetividade do brainstorming nas equipes. 0 problema básico não é o trabalho em equipe em si, mas, antes, os processos sociocognitivos que funcionam no trabal ho em equipe e no modo como as equipes são administradas. Refiro-me a esses problemas como sendo os seguintes: oportunismo social, conformidade, bloqueio à produção e um contexto de norma de rebaixamento.

Oportunismo social. 0 oportunismo social éa tendência de as pessoas, em um grupo, relaxarem - isto é, não trabal harem tão duro, mental ou fisicamente, em um grupo quanto o fariam se estivessem sozinhas. Na verdade, quando os membros organizacionais percebem suas próprias contribuições como indistintas e dispensáveis, el es têm uma probabilidade maior de relaxarem ${ }^{17}$. Se o relaxamento é um desinteresse

\section{Quadro 2: Dados de desempenho entre grupos de brainstorming e indivíduos}

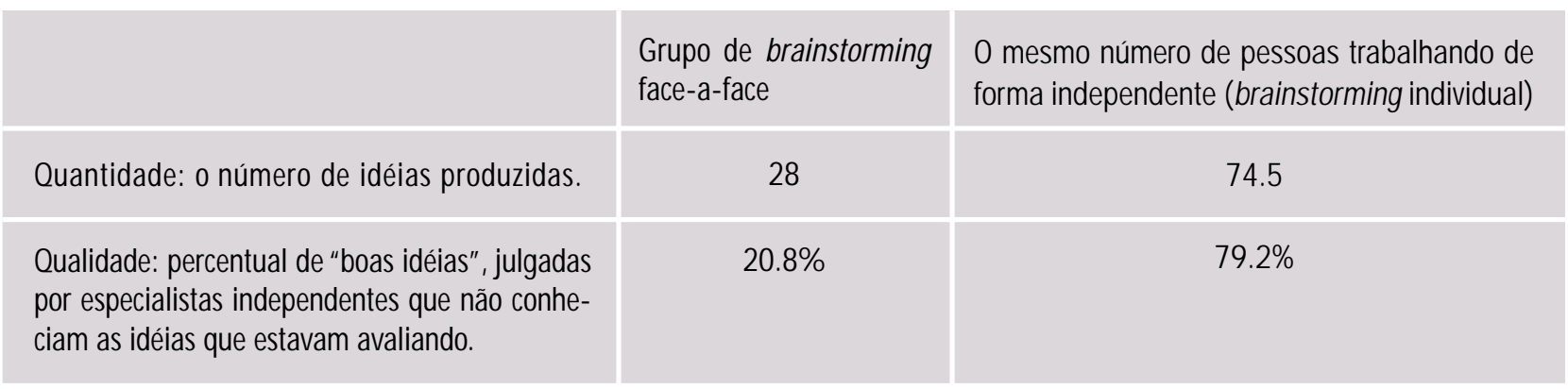

Fonte: Diehl, M. \& Stroebe, W. 1987. Productivity loss in brainstorming groups: Toward a solution of a riddle. Journal of Personality and Social Psychology, 53: 497-509. 
extremo em uma tarefa, então o "fluxo" é um envolvimento e um interesse extremos. De acordo com o psicólogo Mihaly Csikszentmihalyi, as pessoas que realmente gostam de uma tarefa freqüentemente experienciam um estado de "fluxo". A idéia de fluxo é que uma atividade é desafiante o suficiente para ser interessante e recompensadora, mas não tão desafiantea ponto de ameaçar ou inibir o participante. Fluxo éa experiência de gostar tanto de uma atividade que se torna válido realizá-la, mesmo que não tenha conseqüências além de seu próprio contexto ${ }^{18}$. Dessa forma, o processo é mais importante do que o resultado para as pessoas que estão em um estado de fluxo.

Conformidade. Um princípio humano básico éo desejo de ser amado e aceito pelos outros; em particular, pelos grupos a que se pertence. Diversas teorias do comportamento social (por exemplo, a teoria da identidade social) fornecem fortes evidências sobre o fato de que as pessoas buscam se identificar com os grupos e que vão se envolver em comportamentos às vezes excêntricos a fim de garantir sua aceitação pelo grupo ${ }^{19}$. Nas equipes de brainstorming, isso significa, por exemplo, que os executivos podem ser cautelosos na apre-
Por meio de associação livre, alguém sugeriu a palavra "utensílio". Isso levou a "garfo". Um participante fez uma piada sobre uma sopa que poderia ser comida com um garfo. 0 grupo raciocinou (de uma maneira convergente) que a sopa não poderia ser comida com um garfo, a não ser queela fosse engrossada com vegetais e carne - e a Campbell's Chunky Soups, uma linha de produtos com um sucesso extraordinário, nasceu ${ }^{21}$.

A conformidade pode ocorrer quando os membros do grupo estiverem preocupados com o fato de os outros membros serem críticos em relação a suas sugestões, apesar das instruções que forem dadas com o intuito de minimizar essas preocupações ${ }^{22}$. M uitas convenções sociais nas empresas sugerem que as pessoas deveriam se manter on topic e não apresentar idéias que possam ter grande divergência daquelas que estão sendo discutidas. Isso normalmentenão é uma boa idéia quando se fala de pensamento criativo.

Bloqueio à produção. Uma pessoa trabal hando sozinha em um problema pode desfrutar do benefício de um fluxo não interrompido de pensamento. Em contraste, os membros do grupo de brainstorming não podem falar ao mesmo tempo, mas, pelo contrário, têm de esperar por sua vez para falar. Conseqüentemente, as pessoas podem esquecer suas idéias ou decidir não apresentá-las durante o período de espera ${ }^{23}$. Sua produção de idéias é bloqueada. Com certeza pode ser frustrante ficar esperando, especialmente se a reunião não for bem conduzida. 0 blo-

sentação de suas idéias e sugestões por temerem que os outros as avaliem negativamente ${ }^{20}$. Isso, é claro, leva os membros a sugerirem idéias "apropriadas", tradicionais, conservadoras ealtamente semelhantes - exatamente o tipo decomportamento que a maioria das organizações gostaria de evitar. Por exemplo, estudos de associação de palavras revelam que as pessoas dão respostas mais convencionais eusam mais clichês quando estão em um grupo do que quando estão sozinhas. Algumas empresas têm liberado suas equipes para usarem exercícios de associação livre. Por exemplo, na Campbell's Soup Company, um grupo de desenvolvedores de produtos começou a fazer um brainstorming selecionando, al eatoriamente, a palavra "maçaneta" de um dicionário. queio à produção funciona da mesma forma no grupo, pois é difícil para os membros do grupo ouvirem e processarem as idéias geradas pelos outros membros enquanto estiverem gerando suas próprias idéias.

Contexto de norma de rebaixamento. É comumente observado que o desempenho das pessoas que trabalham em um grupo tende a convergir ao longo do tempo. Por exemplo, na CDW - Computer Discount Warehouse - o pessoal devendas que trabalha na mesma área do prédio faz relatórios mensais sobre as cifras das vendas de forma mais semeIhante uns dos outros do que aquelas pessoas que trabal ham em outros prédios e áreas ${ }^{24}$. Até aqui, nenhum problema. 
Contudo, há uma sutil tendência de que as pessoas com desempenhos mais baixos dentro de um grupo puxem para baixo a média. De fato, indivíduos trabalhando em grupos de brainstorming tendem a igualar seu desempenho àquele do membro menos produtivo, também conhecido como contexto de norma de rebaixamento ${ }^{25}$. Esse contexto tem uma probabilidade maior de ocorrer quando não há fortes incentivos internos ou externos para um alto desempenho nas equipes ${ }^{26}$. Esse baixo nível de desempenho pode ser estabelecido como o benchmark para a equipe, no que passará a ser visto como um nível apropriado ou típico de desempenho. Por exemplo, os participantes de duplas ou de grupos interativos de quatro membros tendem a se tornarem mais semeIhantes em sua taxa de geração de idéias do que os grupos não-interativos ${ }^{27}$. Infelizmente, os membros menos produtivos da equipe são freqüentemente mais influentes na determinação dos diversos desempenhos da equipe do que os de meIhor desempenho.

O que ocorre durante uma típica sessão de brainstorming? 0 que exatamente poderíamos esperar encontrar em uma sessão típica de brainstorming empresarial? Interações gravadas em vídeo e em tape revelam um interessante conjunto de eventos. Os quatro problemas observad os acima combinam-se para fazer com que as pessoas, na maioria dos grupos de brainstorming:

- experimentem inibições, ansiedade e preocupações com a auto-apresentação

- diminuam a produtividade

- participem de rituais sociais, tais como contar histórias, repetir idéias e dar feedbacks positivos (um pad rão natural da conversação que funciona muito bem em festas, mas que mata a criatividade)

- estabeleçam seus benchmarks de desempenho em níveis muito baixos

- conformem-se em termos de idéias

- conformem-se em termos da taxa de geração de idéias
A ilusão do desempenho sem falha . A maioria das equipes de brainstorming não tem idéia de que esses comportamentos estão ocorrendo, o que significa que as equipes mais interativas sentem grande confiança sobre sua produtividade. Assim, embora a estima do grupo tenha sido suavizada pelos rituais sociais, ela possui uma base defeituosa. Os grupos de brainstorming e as empresas que os usam são seu próprio e pior inimigo: tornam-se presas da ilusão de que estão funcionando muito eficientemente. Sofrem de ilusões de invulnerabilidade, racionalização coletiva, crençana moralidade do grupo, e estereotipias dos grupos externos. Na verdade, a ilusão de desempenho é tão automática que as pessoas freqüentementeatribuem méritos às idéias geradas pelos outros ${ }^{28}$.

\section{Quase todos os estudos de laboratório revelaram} que um grupo de brainstorming leva à produção de menos idéias do que um número comparável de membros fazendo brainstorming individual.

Construindo a criatividade da equipe. Felizmente, há ações que as equipes podem adotar com o intuito de se precaverem contra os problemas típicos produzidos pelo brainstorming. As dez sugestões destacadas abaixo baseiamse em poderosas pesquisas científicas, bem como em dados práticos. Além do mais, a maioria das técnicas assinaladas não custa muito dinheiro. Seguem as dez sugestões:

1. Diversificação da equipe. Os membros da equipe que possuem diferentes experiências, formação eperspectivas vão naturalmente oferecer diferentes categorias de pensamento e formas de considerar um problema, em contraposição às equipes mais homogêneas. Quanto mais heterogênea for a equipe, maior será a probabilidade de seus membros se destacarem em todas as medidas de criatividade. Defato, as equipes cujos membros forem diversificados em termos de experiências e perspectivas irão ter um desempenho superior ao das equipes com membros homogêneos nas tarefas que exigirem uma solução criativa e inovadora de problemas ${ }^{29}$. As equipes com membros heterogêneos produzem mais argu- 
mentos, aplicam um número maior de estratégias, detectam mais novas soluções e são melhores na integração de múltiplas perspectivas do que as equipes sem confronto de perspectivas. Por exemplo, a empresa de design Ideo deliberadamente contrata pessoas com experiências diversificadas. Uma ilustração maravilhosa do funcionamento do conceito deequipe diversificada é encontrada nos laboratórios de microbiologia. Dunbar empreendeu um sólido e exaustivo estudo dos laboratórios demicrobiologia duranteum extenso período detem$\mathrm{po}^{30}$. Ele participou de todos os encontros e gravou, com esmero, todas as interações, formais e informais, em sua busca pelas condições que poderiam gerar criatividade. Ao longo do tempo, al gunslaboratórios sedistinguiram por terem feito mais descobertas de ruptura, tal como evidenciado pelo número de patentes. Esses laboratórios bem-sucedidos em termos de desenvolvimento de novas patentes não possuíam uma equipe de apoio muito grande, nem eram cientistas melhor pagos ou mais inteligentes. A diferença-chave envolvia a diversidade de formação dentro dos grupos. As equipes que eram mais he terogêneas em sua composição tinham uma probabilidade maior de se engajarem no pensamento divergente, aprendido com seus erros, espontaneamente se baseando em outros domínios para equacionar seus problemas.

conseguem reconhecer quando um conceito particular conhecido poderia ser útil para resolver um novo problema, a criatividade pode ser real çada. 0 problema é que não é fácil transferir a informação relevante de um domínio para outro as pessoas tendem, quase sempre, a resolver problemas baseadas exclusivamente em seu nível superficial de similaridade com outras situações, e não em sua similaridade mais profunda ou estrutural.

Esta tendência aponta para um grave problema com a equipe de trabalho criativa: as pessoas normalmente possuem o conhecimento de que precisam para resolver problemas, mas elas não conseguem acessá-lo porque ele tem origem em um contexto diferente. Por exemplo, quando édado às pessoas o "problema do tumor" (dizendo respeito a como usar um raio para destruir o tumor do paciente, sem que a intensidade do raio pudesse destruir o tecido saudável em redor do tumor), uma solução elegante (mas não óbvia) envolve usar uma série de raios de baixa intensidade, a partir de diferentes ângulos, de modo que todos tivessem como destino a convergência sobre o local do tumor ${ }^{32}$. Somente uns $10 \%$ das pessoas resolvem esse problema. Gick eH olyoak questionaram se o desempenho aumentaria se fosse dado de antemão aos participantes um problema análogo, envolvendo a tentativa de um general para tomar umafortaleza, sem que pudesse fazer uso do exército inteiro para um ataque frontal. Uma solução elegante (e análoga) é dividir o exército em pequenas tropas de solo e ordenar que cada uma del as se aproxime da fortaleza a partir de estradas di-

2. Raciocínio analógico. 0 raciocínio analógico é 0 ato de aplicar um conceito ou idéia de um domínio particular em outro domínio. A mais simples analogia poderia ser alguma coisa como isto: " $O$ verde surge quando o vermelho desaparece". Uma analogia muito mais complexa é a aplicação, por Kepler, dos conceitos de luz para o desenvolvimento de uma teoria do movimento orbital dos planetas ${ }^{31}$. De modo similar, o químico Friedrich Kekulé descobriu a estrutura hexagonal fechada do anel de benzeno imaginando uma cobra mordendo seu próprio rabo. $\mathrm{N}$ a medida em que as equipes ferentes, ao mesmo tempo. Mesmo quando o problema do tumor foi apresentado imediatamente depois do problema da fortal eza, somente $41 \%$ das pessoas transferiram, espontaneamente, a solução de "primeiro dividir e então convergir". Na pesquisa realizada em nosso laboratório, demonstramos uma similar falta de transferência com executivos ${ }^{33}$. Assim, aplicar um conhecimento previamente aprendido a novas situações é algo surpreendentemente difícil para a maioria dos executivos. Isso é conhecido como o problema do "conhecimento inerte". 
Muitas empresas estão reconhecendo o potencial dequebra de padrões oferecido pelo raciocínio analógico como um modo de usar as idéias que as pessoas têm sobre outras coisas, aparentemente não relacionadas, para resolver os urgentes problemas dos negócios. Alan Heeks, formado em MBA por Harvard, que trabalhou na Procter \& Gamble, usa uma fazenda orgânica como modelo para a vida dos negócios. Heeks foi muito longe para dar workshops em uma fazenda de 132 acres onde as analogias eram exuberantes - os participantes refletiam sobre a colheita de seu futuro desenvolvimento, reciclagem, fertilidadee sustentabilidade. Heeks ajudava os participantes a extraírem analogias entre o solo e 0 staff da empresa ${ }^{34}$.

A Câmara deN egócios da Pensilvânia, no centro de Harrisburg, é uma ampla associação que representa as mais de 6,5 mil empresas na Pensilvânia que fazem uso da força de trabal ho privada. A organização escolheu o romance River horse, de William Least HeatMoon, como uma analogia para as mudanças e transformações pelas quais está passand o ${ }^{35}$. 0 presidente da Câmara, Floyd Warner, selecionou o livro para seu grupo ler e discutir regularmente.

Outro uso da analogia: quando a Nasa considerou necessário projetar um satélite que seria amarrado a uma estação espacial por um fino cabo de 60 milhas de comprimento, os projetistas perceberam que o movimento vacilante do satélite o faria agir como um pêndulo com um arco de movimento muito amplo. 0 cientista Thomas Kane, de Stanford, usando a anal ogia de um ioiô, determinou que um pequeno motor elétrico no satélite faria com que ele se movesse lentamente pelo cabo até a estação espacial ${ }^{36}$.

Existe também o exemplo de um fabricante de batatas fritas que tinha um problema freqüente: as batatas fritas ocupavam muito espaço na prateleira quando eram empacotadas de forma solta e esfarelavam-se quando empacotadas em embalagens menores. 0 fabricante descobriu uma solução usando uma analogia direta: folhas secas são muito parecidas com batatas fritas. Elas esfarelam muito facilmente e são volumosas. Folhas prensadas são largas e delgadas. As batatas fritas poderiam ser preparadas de forma larga e delgada? Do modo como eram produzidas, não. Contudo, a equipe percebeu que as folhas não eram prensadas quando secas, mas quando úmidas. Assim, eles embalaram as batatas fritas em pilhas, úmidas o bastante para não se esfacelarem, mas secas o bastante para ficarem quase lisas e del gadas. 0 resultado foi a Pringles ${ }^{\mathrm{T} \mathrm{M}}, 37$

Prem Kamath, chefe do departamento de recursos humanos da Hinustan Lever, descreveu como sua empresa usa as analogias do filme Tora! Tora! Tora! para se prevenir contra a complacência ${ }^{38}$. E Barry Schuler, vice-presidente sênior de 
estratégia e planejamento de recursos de informação da Marriott International, tem ajudado tecnicamente os executivos da Marriot falando em forma de analogias. Schuler, um dos primeiros pilotos de race, vendeu a nova rede com a seguinte anal ogia: "Bill M arriottJr. (CEO echairman do board) era dono de muitos carros exóticos. Ele adorava falar sobre carros. Eu lhe disse que a infra-estrutura - o hardware e 0 sistema de software conectando à rede - [é] como a estrada. Então Ihe perguntei: 'Por que você desejaria uma centena de estradas indo atéo mesmo lugar, quando vocêpode ter uma?'. Comparo nossos serviços a caminhões e carros sendo dirigidos pela estrada. E o pessoal do departamento de recursos de informação como o pessoal de assistência"39. Um raciocínio análogo envolve a aplicação de diversas categorias a um problema ou desafio presente da empresa. Outro exemplo: a agência de publicidade D'Arcy freqüentemente realiza "seqüestros", pelos quais os empregados são subitamente levados às pressas para museus e então inquiridos para que pensem em um artista ou exibição qual quer como uma anal ogia para seu produto ou serviço atual ${ }^{40}$.

que o brainwriting, seguido de uma rodada de troca, elimina o problema do bloqueio à produção e do oportunismo social quando comparado ao brainwriting padrãa $0^{42}$. Particularmente, tenho empregado essa técnica na sala de aula e obtido reações estranhas: os executivos sentem-se desconfortáveis ao ficarem em silêncio; eles afirmam que isso quebra seu ritmo. Mas a técnica tem seu mérito: os grupos debrainwriting produzem consistentemente mais e melhores idéias do que os grupos que seguem seus instintos naturais. É válido observar que, ainda que o facilitador não use o brainwriting per se, fazer interrupções podeser quasetão efetivo quanto. Mesmo que os membros do grupo não escrevam nada, fazer rápidas interrupções pode servir como uma função similar ao brainwriting ${ }^{43}$. Quanto mais silêncios e pausas ocorrem, maior a probabilidade de que um ciclo divergente seja criado.

4. Técnica do grupo nominal. Esta éuma variação da técnica de brainwriting padrão ${ }^{44}$. Começa com uma sessão inicial debrainwriting, independentemente de seescreverem ou não idéias. Essas idéias são posteriormente partilhadas pelo grupo por meio de uma rodada e sintetizadas em um quadro-negro. Em seguida, o grupo discute as idéias com o intuito de esclarecimento e avaliação. Finalmente, há um processo de votação individual a fim de classificar as idéias. Incidentalmente, a técnica foi comparada a um processo de brainstorming

3. Brainwriting. 0 Brainwriting funciona desta forma: em vários pontos-chave, eno momento apropriado, duranteuma sessão de brainstorming, todos os membros do grupo param de falar e escrevem suas próprias idéias silenciosamente ${ }^{41}$. Escrever as idéias no lugar de falá-las el imina o problema do bloqueio à produção, visto que os membros do grupo não têm de esperar sua vez para produzir idéias. Pode também reduzir a conformidade, já que o formato deescrita el imina a necessidade da fala pública eétipicamentemais anônimo do que o brainstorming oral. As idéias escritas podem ser posteriormente partilhadas pelo grupo numa rodada e resumidos em um quadro negro ou flipchart. Por exemplo, investigações de grupos de brainstorming de quatro pessoas revelaram interativo, e a técnica do TGN superou completamente 0 desempenho do grupo de brainstorming padrão ${ }^{45}$. Da mesma forma, os grupos nominais que funcionam na mesma sala produzem mais idéias do que os em salas separadas ${ }^{46}$. Uma variante do TGN é a técnica do grupo nominal anônimo. $\mathrm{Na}$ técnica, os membros primeiro escrevem suas idéias em folhas de papel individuais ou em cartões de papel. 0 facilitador do encontro, ou um membro do grupo, recolhe os papéis, mistura-os e os redistribui al eatoriamente aos indivíduos, que lêem os papéis em voz alta ou discutem em pequenos grupos. Essa variação gera grande aceitação das idéias alheias, pois as idéias são semi-anônimas e impedem que os membros individuais do grupo defendam apenas suas próprias idéias. 
O utra variante da técnica de grupo nominal éa Delphi. $\mathrm{Na}$ técnica Delphi, os membros do grupo não interagem face-a-face em nenhum momento. Essa técnica éidealmente recomendada para grupos cujos membros estão geograficamente dispersos, tornando difícil a participação nos encontros, epara equipes cujos membros passam por um conflito tão grande que se torna difícil terminar um encontro. Essa técnica requer um líder ou facilitador que tenha a confiança dos membros da equipe. 0 processo inteiro ocorre por meio de questionários seguidos de feedback, que pode ser por computador. 0 líder distribui um assunto ou uma questão para os membros e solicita que cada membro da equipe responda. 0 líder agrega então as respostas, envia-as de volta para a equipe e solicita feedback. Esse processo é repetido até que haja uma solução para o ponto em questão.

A técnica Delphi fornece uma estrutura máxima, assegura inserções iguais e impede o bloqueio à produção - é muito fácil evitar a perda de coordenação quando os membros da equipe nunca interagem diretamente! A técnica é uma boa alternativa para as equipes que estão fisicamente separadas mas que, não obstante, precisam tomar decisões. Já que os membros respondem de forma independente, as pressões para conformidadee o medo de avaliações são limitados. Um problema associado com essa técnica, que não está associado com o brainstorming regular ou com o nominal, é que ela pode consumir muito tempo. As sessões podem durar vários dias, até mesmo semanas.

5. Criando uma memória organizacional. Uma das coisas que mais prejudicam o desempenho éa repetição de idéias ou seu esquecimento. Os grupos criam memória organizacional gravando as idéias in full view. Os membros dos grupos freqüentementeperdem maistempo repetindo idéias quando elas não estão indexadas fisicamente. Quando se gravam todas as idéias, uma sessão debrainstorming melhora muito. Por exemplo, o Buckman Laboratories Inc., uma empresa de especialidades químicas para sistemas industriais aquosos, com sede em Memphis, Tennessee, conecta todos seus associados espaIhados pelo mundo com uma rede de conhecimento de sua propriedade, o K'N etix ${ }^{47}$. Da mesma forma, a equipe de migração da Sun Microsystems' Java criou uma biblioteca partiIhada de códigos que serve como uma central de comunicação, a partir da qual podem checar porções inteiras de códigos de software em vez de recriá-los toda vez ${ }^{48}$.
No momento em que as equipes conseguem reconhecer quando um conceito particular conhecido pode ser útil para resolver um novo problema, a criatividade pode ser realçada.

6. Facilitadores preparados. Um facilitador preparado pode acompanhar melhor as regras do brainstorming, ajudar a criar uma memória organizacional e manter as equipes nos triIhos, no sentido de garantir que as normas de rebaixamento não ocorram. Defato, os facilitadores preparados podem elevar o nível de desempenho da equipe até aquele dos grupos nominais ${ }^{49}$. Além disso, pode haver benefícios de longo prazo para esse investimento: as equipes que são orientadas por facilitadores em várias sessões de produção de idéias criativas apresentam alto nível de produtividade em subseqüentes sessões sem facilitadores ${ }^{50}$. O s facilitadores podem ensinar as equipes a partilharem idéias sem uma interação social extensa ou "enrolação". Por exemplo, na empresa de design Ideo, os líderes grupais são usados para facilitar todas as sessões de brainstorming. De acordo com seus executivos, a qualificação-chave para os facilitares éque sejam "bons com grupos", e não que sejam especialistas na área particular do produto.

7. Benchmarks elevados. Os grupos de brainstorming fre qüentemente possuem um desempenho inferior porque não possuem benchmarks relevantes. A informação sobre níveis de atividades de outros membros pode aumentar o desempenho desde que o benchmark não seja muito discrepante ${ }^{51}$. Dar aos participantes do brainstorming altos padrões de desempenho aumenta significativamente 0 número de idéias produzidas ${ }^{52}$. Mesmo quando os membros estiverem trabaIhando de forma independente e anunciando aos outros a quantidade de idéias que geram a cada cinco minutos, o nú- 
mero de idéias geradas pela equipe é aumentado ${ }^{53}$. Similarmente, um facilitador pode, de forma periódica, chamar a atenção dos participantes do brainstorming para um gráfico na tela do computador, indicando como se compara o desempenho da equipe com o de outras equipes. Esse feedback aumenta, significativamente, o número deidéias geradas pelo grup ${ }^{54}$. Até mesmo a simples advertência de que as equipes verão o desabrochar de todas as idéias no final da sessão aumenta o número de idéias singulares geradas ${ }^{55}$. É também útil para os membros recordarem de suas próprias idéias depois do brainstorming.

8. Mudança de membro. Os grupos normalmente não permanecem completamente intactos; pelo contrário, membros entram e saem dos grupos ${ }^{56}$. Meu colega Hoon-Seok Choi e eu examinamos extensivamente os pequenos grupos que permaneciam perfeitamente intactos (isto é, turnover zero) versus grupos que passaram por pelo menos uma mudança de membro (mantendo o número total de pessoas). Encontramos uma evidência dramática de que os grupos que passam por mudanças de membros (ou seja, a saída de um antigo membro ea entrada deum novo) geram maisidéias (maior fluência) e mais tipos diferentes de idéias (maior flexibilidade) do que os grupos que permanecem intactos. Eis o que pensamos que acontece: os grupos que se mantêm unidos, para olharem para si mesmos de modo mais consciencioso. Isto é, a presença de um novo membro pode motivar os que ali estão há muito tempo a revisitarem sua estratégia de ação e desenvolverem métodos novos e aprimorados para realizar as tarefas do grupo ${ }^{57}$. Nesse ponto, pensamos que o grupo está em uma melhor posição não somente para pensar sobre seu estilo de funcionamento, mas também para aprender com os outros. Finalmente, os grupos que passam por uma mudança de membros são mais orientados para a tarefa do que os grupos que mantêm os mesmos membros, eisso devido à natureza transitória da interação entre os membros do grupo em que houve a mudança58.

A técnica da escada é uma variante da técnica de mudança de membros. Nela, os membros são acrescentados, um a um, na equipe ${ }^{59} .0$ primeiro passo da técnica envolvea criação de um subgrupo de duas pessoas (o núcleo), que começa uma discussão preliminar sobre a tarefa do grupo. Depois deum intervalo fixo detempo, outro membro sejunta ao grupo nuclear e apresenta suas idéias a respeito da tarefa. 0 grupo detrês pessoas discute então a tarefa de uma maneira também preliminar. 0 processo continua até que todos os membros tenham sistematicamente se juntado ao grupo nuclear. Quando isso ocorrer, o grupo chega a uma solução final. Cada membro do grupo deve ter tempo suficiente para pensar sobre o problema antes de entrar no grupo nuclear. Mais importante: os membros que vão entrando devem apresentar suas soluções preliminares antes de ouvir as soluções preliminares do grupo nuclear. Uma decisão final não pode ser alcançada até que o grupo tenha se formado em sua totalidade. Os grupos de escada auto-ritmados (que vão se formando por meio de passos a um ritmo autodeterminado) produzem decisões

sem qual quer mudança na associação, desenvolvem um tipo de artrite cognitiva - mantêm-se fixos em sua velha e idêntica rotina quando diante da geração de idéias. Em contraste, os grupos que passam pela mudança de um membro são naturalmente expostos a mais idéias devido à maior diversidade nas habilidades e informações rel evantes para a tarefa. Além disso, quando um grupo passa por uma mudança de membros, os antigos membros ficam em uma posição única grupais de qualidade significativamentemaior do que os grupos convencionais $s^{60}$. Os membros com as melhores decisões individuais exercem mais influência nos grupos de escada do que em grupos com livre interação.

9. Brainstorming eletrônico. Também conhecido como BSE, o brainstorming eletrônico faz uso de computadores para interagir e trocar idéias. Em uma sessão BSE típica, os mem- 
bros ficam sentados em volta de uma mesa com estações individuais de computador. Uma tela maior projeta todas as idéias geradas pelos membros. Já que os membros não têm de concorrer para ter a palavra, o bloqueio à produção é virtualmente eliminado. E já que as idéias são postadas anonimamente, a conformidade é eliminada.

A Mattel Media usa uma variação interessante do brainstorming eletrônico em seus encontros de equipe. Um autoproclamado "tecnografista" registra as idéias de novos produtos dos membros da equipe em um laptop - as entradas aparecem atrás do grupo, seja em um monitor colorido de 35 polegadas, ou na parede. Bernie DeKoven, cujo cargo na Mattel era doctor fun /staff design, em uma tentativa de minimizar os bloqueios à produção, não permitia que ninguém escrevesse (baseado na crença de que, se al guém está escrevendo, não está pensando). Desse modo, o tomador de notas registra as idéias de todo mundo na frente do grupo. Essas idéias podem ser calculadas, avaliadas e, eventualmente, jogadas fora. Além do mais, todo mundo deixa o encontro com uma cópia das anotações em mãos - servindo, assim, para a memória organizacional. Em acréscimo, DeKoven mantinhaum "depositário" um arquivo das idéias rejeitadas nos encontros. Algumas dessas noções dispensadas se tornavam valiosas mais tarde, no contexto de outros projetos. Por exemplo, quando Andy Rifkin, vice-presidente sênior de desenvolvimento criativo da Mattel Media, estava passeando com compradores de brinquedos, recebeu repetidos pedidos para desenvolver brinquedos baseados em atividades para os garotos. Recorrendo ao depositário de um encontro de um ano atrás, ele encontrou o conceito de um CD-ROM hot wheels para projetar e decorar carros e imprimir licenças etickets. $\mathrm{O}$ Hot W heel Custom Car Designer tornou-se um item de melhor venda nas lojas. ${ }^{61}$

10. Construa um playground. Uma das abordagens mais populares para estimular a criatividade no curto prazo, bem como de instilar paixão e motivação de longo prazo, éa criação de um playground no trabalho. Não há uma única receita para ele. A idéia básica é quebrar as vel has idéias sobre o que significa estar no trabalho. No playground, paredes beges transformam-se em lonas com formato de tendas; elevadores "de bate papo descontraído" são substituídos por escadas rolantes que instigam a conversação; e as áreas de brainstorming (chamadas de "zonas de animação" no escritório) são pintadas em tonalidades tecnicolor funky ${ }^{62}$. Mais importante: a funcionalidade orienta o divertido playground.

O s espaços designados para incentivar a criatividade envolvem muitos elementos de diversão. Por exemplo, a agência de publicidade ao sul da Califórnia, Foote, Cone \& Belding, reinventou o espaço detrabalho tradicional com 156 pranchas desurf na parede de sua sala de reuniões, removendo todas as portas dos escritórios e instalando quadras com bolas de basquete e de bocce italiano que são usadas para brainstormings criativos ${ }^{63}$. Em St. Louis, empregados da agência de publicidade D'Arcy Masius Benton $\&$ Bowles escalam montanhas, visitam museus de arte e assistem a filmes durante o tempo em que estão na empresa, e os executivos da Aurora Foods encorajam os trabalhadores a escreverem nas paredes com canetas de marcar e a ensaiar com os Play-Doh and Slinkies ${ }^{64}$.

\section{significativamente o número de idéias produzidas.}

Ao mesmo tempo em que há pouca ou nenhuma pesquisa sobre se as quadras de bocce aumentam a criatividade, há um poderoso corpo de pesquisas sugerindo que 0 afeto positivo - que surge quando se assiste a um desenho animado ou se vê o filho brincar - aumenta a criatividade ${ }^{65}$. 0 negócio do espaço étão sério que al gumas empresas, como a Steelcase, têm sido pioneiras na construção dos novos espaços de trabalho do futuro. Os "espaços de inovação", designados pela Steelcase, têm transformado o modo como a British Petroleum busca petróleo e o modo como a ultramoderna empresa de moda Prada vende suas roupas para seus clientes ${ }^{66}$.

Criatividade como parte da cultura. As equipes podem ser muito mais criativas do que freqüentemente são. 


\section{Quadro 3: Como as estratégias-chave lidam com as maiores ameaças ao trabalho em equipe criativo}

\begin{tabular}{|c|c|c|c|c|}
\hline \multicolumn{5}{|c|}{ AMEAÇAS À CRIATIVIDADE } \\
\hline & Oportunismo social & Conformidade & Bloqueio à produção & $\begin{array}{l}\text { Contexto de norma de } \\
\text { rebaixamento }\end{array}$ \\
\hline $\begin{array}{l}\text { Diversificação da } \\
\text { equipe }\end{array}$ & & $\begin{array}{l}\text { Equipes diversificadas } \\
\text { têm menor probabili- } \\
\text { dade de ter normas } \\
\text { grupais comuns }\end{array}$ & & \\
\hline Raciocínio analógico & & $\begin{array}{l}\text { Pode levar as equipes a } \\
\text { pensarem sobre idéias di- } \\
\text { ferentes enão tradicionais }\end{array}$ & & \\
\hline Brainwriting & $\begin{array}{l}\text { Especialmente útil se os } \\
\text { membros individuais do } \\
\text { grupo forem responsáveis }\end{array}$ & $\begin{array}{l}\text { Os membros não são } \\
\text { influenciados pelos } \\
\text { outros }\end{array}$ & $\begin{array}{l}\text { Qualquer um pode ser } \\
\text { produtivo ao mesmo } \\
\text { tempo }\end{array}$ & $\begin{array}{l}\text { Os indivíduos não estão } \\
\text { cientes sobre o desem- } \\
\text { penho dos outros }\end{array}$ \\
\hline $\begin{array}{l}\text { Técnica de grupo } \\
\text { nominal }\end{array}$ & $\begin{array}{l}\text { Os indivíduos se sentem } \\
\text { responsáveis }\end{array}$ & $\begin{array}{l}\text { Os membros não são in- } \\
\text { fluenciados pelas idéi- } \\
\text { as dos outros }\end{array}$ & $\begin{array}{l}\text { Qualquer um pode ser } \\
\text { produtivo ao mesmo } \\
\text { tempo }\end{array}$ & $\begin{array}{l}\text { Membros menos dis- } \\
\text { postos a igualarem seu } \\
\text { desempenho }\end{array}$ \\
\hline $\begin{array}{l}\text { Criando memória } \\
\text { organizacional }\end{array}$ & & & $\begin{array}{l}\text { Os membros do grupo têm } \\
\text { uma probabilidade menor } \\
\text { de repetirem idéias }\end{array}$ & \\
\hline $\begin{array}{l}\text { Facilitadores } \\
\text { preparados }\end{array}$ & $\begin{array}{l}\text { Facilitadores preparados } \\
\text { devem manter a motiva- } \\
\text { ção em alta }\end{array}$ & $\begin{array}{l}0 \text { facilitador preparado } \\
\text { deve usar estratégias } \\
\text { para evitar a conformi- } \\
\text { dade }\end{array}$ & $\begin{array}{l}\text { Os facilitadores prepa- } \\
\text { rados devem usar estra- } \\
\text { tégias para evitar o blo- } \\
\text { queio à produção }\end{array}$ & \\
\hline Benchmarks elevados & $\begin{array}{l}\text { Objetivos claros e eleva- } \\
\text { dos reduzem o oportu- } \\
\text { nismo ou desocupação }\end{array}$ & & & $\begin{array}{l}\text { Cada membro será lem- } \\
\text { brado sobreo benchmark; } \\
\text { o benchmark servirá } \\
\text { como um objetivo-chave }\end{array}$ \\
\hline $\begin{array}{l}\text { Mudança de mem- } \\
\text { bros }\end{array}$ & $\begin{array}{l}\text { Os indivíduos podem } \\
\text { ter probabilidade me- } \\
\text { nor de relaxarem quan- } \\
\text { do novos membros es- } \\
\text { tiverem presentes }\end{array}$ & $\begin{array}{l}\text { As normas do grupo po- } \\
\text { dem ser a nalisadas } \\
\text { mais minuciosamente } \\
\text { (menor conformidade) }\end{array}$ & & $\begin{array}{l}\text { As equipes se expõem } \\
\text { a diferentes e poten- } \\
\text { cialmente altos bench- } \\
\text { marks }\end{array}$ \\
\hline $\begin{array}{l}\text { Brainstorming } \\
\text { eletrônico }\end{array}$ & & $\begin{array}{l}\text { Remoção da pressão do } \\
\text { grupo, devido a um maior } \\
\text { anonimato (percebido) }\end{array}$ & $\begin{array}{l}\text { Virtual e completamen- } \\
\text { te eliminado }\end{array}$ & \\
\hline Criar um playground & $\begin{array}{l}\text { Se as pessoas forem } \\
\text { motivadas e desafiadas } \\
\text { haverá menor probabili- } \\
\text { dade de ficarem desocu- } \\
\text { padas na equipe }\end{array}$ & $\begin{array}{l}\text { Espaços não-confor- } \\
\text { mistas levam ao com- } \\
\text { portamento não confor- } \\
\text { mista }\end{array}$ & & \\
\hline
\end{tabular}


As práticas tradicionais de administração, tais como pedir sugestões, uma única pessoa falar por vez, e avaliar as alternativas antes de esgotá-las, prejudicam, em vez de facilitar, 0 trabalho de equipe criativo. As dez estratégias que analisamos podem ser aplicadas a um amplo espectro de grupos, desde equipes que não sofrem mudanças de membros, de longo prazo e com trabal ho intensivo, até os grupos eencontros ad hoc. 0 Q uadro 3 resume as dez estratégias que discutimos e indica a ameaça particular à criatividade para a qual cada uma delas se volta.

0 trabalho de equipe criativo não é bom apenas para 0 bottom line, mas pode ser também uma experiência intensamente recompensadora. 0 paradoxo é que a maioria denossos instintos sobre criatividade está errada. 0 uso de idéias que sejam criativamente real istas exige que as empresas apóiem equipes que façam coisas com propósito e sentido, tais como se esforçar pela quantidade (ao invés de pela qualidade) pelo menos inicialmente; sugerir idéias deliberadamente impossíveis de serem realizadas; e criar um abrigo para 0 pensamento individual. Os grupos e as equipes podem ter sucesso com a criatividade, mas os quatro desafios à criatividade - oportunismo social, conformidade, bloqueio à produção e contexto de norma de rebaixamento - podem matar a mais cândida tentativa de criatividade. As dez sugestões para realçar a criatividade não têm a etiqueta com preços caros; o principal desafio será fazer delas parte da cultura de uma equipe criativa.

\section{Leigh Thompson}

Profa. de Administração na N orthwestern University.

E-mail: leighthompson@kellogg.nwu.edu

\section{Texto traduzido por Pedro Fernando Bendassolli}

Artigo originalmente publicado na Academy of M anagement Executive, v. 17, n. 1, p. 96-111, Fev. 2003.

Copyright 2003 Academy of M anagement. Todos os direitos são reservados. Nenhuma parte deste artigo pode ser reproduzida por qualquer meio ou forma sem a permissão por escrito da Academy of Management. Para obter autorização entre em contato com Copyright Clearance Center:www.copyright.com.

\section{Notas}

1. Ver FRANK, R. H. e COOK, P. J. The winner-take-all society: why the few at the top get so much more than the rest of us. (Reprint edition). New York : Penguin, 1996.
2. Ver BRANDENBURGER, A. M. e NALEBUFF, B. J. Co-opetition. N ew York : Doubleday, 1996.

3. GUILFORD, J. P. Creativity. American Psychologist, n. 5, p. 444-54, 1950.

4. Ver FINKE, R. A. Creative realism. In: Smith, S. M., Ward, T. B. e Finke, R. A. (Eds.). The creative cognition approach. Cambridge: MIT Press, 1995. p. 303-26.

5. De forma contrária à intuição popular, a idéia de Edison não foi inesperada. Seu sistema de iluminação foi uma continuidade dos sistemas de iluminação existentes. Para uma descrição de como ele desenvolveu suas idéias, ver: BASALLA, G. The evolution of technology. N ew York : Cambridge University Press, 1988; W EISBERG, R. W. Casestudies of creativethinking. In: Smith, S. M., Ward, T. B. e Finke, R. A. (Eds.). The creative cognition approach. Cambridge: MIT Press, 1997. p. 53-72.

6. Ver GUILFORD, J. P. Personality. New York : McGraw-Hill, 1959; GUILFORD, J. P. The nature of human intelligence. New York : McGrawHill, 1967.

7. Id. Ibid.

8. Uma das contribuições mais desprezadas do trabalho pioneiro de O sborn sobre brainstorming é sua intuição sobre o relacionamento positivo entre quantidade e qualidade. Osborn corretamente observou que a exigência por "grandes idéias" abafaria o processo criativo. Contudo, é fácil para as pessoas buscarem a quantidade. A probabilidade de ter um única idéia verdadeiramente excelente pode ser diretamente derivada do número de idéias produzidas. Além disso, a probabilidade de se construírem e integrarem idéias pode ser facilitada pela quantidade.

9. Esse exemplo foi sugerido pela professora Terri Kurtzberg, cuja tese foca a criatividade; ela usou amplamente o exercício da caixa de papelão.

10. Ver VERBERNE, T. Creative fitness. Training and D evelopment, p. 6871, 1 Aug. 1997.

11. Ver CAMM, M. Learn how to clap with one hand. Sydney M orning Herald, Sydney, p. 15, 24 March 1994.

12. Ver OSBORN, A. F. Applied imagination. (Rev. ed.). New York : Scribner, 1957.

13. Ver GENDRON, G. FYI: growing by design. Inc., p. 9, May 1998.

14. As revisões metaanalíticas do brainstorming oferecem dados interessantes sobre como os indivíduos se desempenham melhor do que os grupos; um poderoso exemplo é dado em: MULLEN, B., JOHNSON, C. e SALAS, E. Productivity loss in brainstorming groups: a meta-analytic integration. Basic and Applied Social Psychology, v. 12, n. 1, p. 3-23, 1991. Outros artigos que se voltam para esse evidente enigma incluem: DIEHL, M. e STROEBE, W. Productivity loss in brainstorming groups: toward a solution of a riddle. Journal of Personality and Social Psychology, v. 53, n. 3, p. 497-509, 1987; PAULUS, P. B. e DZINDOLET, M. T. Social influence processes in group brainstorming. Journal of Personality and Social Psychology, v. 64, n. 4, p. 575-86, 1993; JABLIN, F. M. Cultivating imagination: factors that enhance and inhibit creativity in brainstorming groups. Human Communication Research, v. 7, n. 3, p. 245-58, 1981; PAULUS, P. B., LAREY, T. S. eORTEGA, A. H. Performance and perceptions of brainstormers in an organizational setting. Basic and Applied Social 
Psychology, v. 17, n. 1-2, 249-65, 1995; TAYLOR, D. W., BERRY, P. C. e BLOCK, C. H. Does group participation when using brainstorming facilitate or inhibit creative thinking? Administrative Science Quarterly, $\mathrm{n}$. 3, p. 23-47, 1958.

\section{Veja MULLEN, JOHNSON, e SALAS, 1991, p. 18.}

16. Vários acadêmicos que têm trabalhado diretamente com equipes em empresas relatam que a maioria das empresas pede para se usar 0 brainstorming. Contudo, a questão de se ele é usado de modo eficiente não está em debate. Para exemplos de como as empresas usam 0 brainstorming, ver: HACKMAN, J. R. Work teams in organizations: an oriented framework. In: Hackman, J. (Ed.). Groups that work and those that don't. San Francisco : Jossey-Bass, 1990; SUTTON, R. I. e HARGADON, A. Brainstorming groups in context: effectiveness in a product design firm. Administrative Science Quarterly, v. 41, n. 4, p. 685718, 1996; SWEZEY, R. W. eSALAS, E. (Eds.). Teams: their training and performance. Norwood : Ablex, 1992; WOODMAN, R. W., SAWYER, J. E. e GRIFFIN, R. W. Toward a theory of organizational creativity. A cademy of Management Review, v. 18, n. 2, p. 293-321, 1993.

17. Uma ampla literatura de pesquisa analisou diversos fatores que poderiam mitigar o poderoso efeito do oportunismo social. Para exemplos desses métodos, ver: BOUCHARD, T. J. Training, motivation, and personality as determinants of the effectiveness of brainstorming groups and individuals. Journal of A pplied Psychology, v. 56, n. 4, p. 324-31, 1972; DIEHL eSTROEBE, 1987; HARKINS, S. G. ePETTY, R. E. Effects of task difficulty and task uniqueness on social loafing. Journal of Personality and Social Psychology, v. 43, n. 6, p. 1214-29, 1982; SHEPPERD, J. A. Productivity loss in performance groups: a motivation analysis. Psychological Bulletin, v. 113, n. 1, p. 67-81, 1993.

18. Ver Csikszentmihaly, M. Finding flow: the psychology of engagement with everyday life. New York : Basicbooks, 1997.

19. Ver os trabalhos de Tajfel sobre a teoria da identidade social, especificamente: TAJFEL, H. Differentiation between social groups: studies in the social psychology of intergroup relations. N ew York : Academic Press, 1978.

20. Ver CAMACHO, L. M. e PAULUS, P. B. The role of social anxiousness in group brainstorming. Journal of Personality and Social Psychology, $v$. 68, n. 6, p. 1071-80, 1995.

21. Ver HIGGINS, J. Creating creativity. Training and Development, v. 48, n. 11, p. 11-5, 1994.

22. As pessoas prestam atenção às pistas de status dentro de um grupo, e, como uma regra geral, membros com menor status conformam-se ao que percebem ser as perspectivas dos membros com maior status. Para análises do efeito de conformidade, ver: COLLAROS, P. A. eANDERSON, L. R. Effect of perceived expertness upon creativity of members of brainstorming groups. Journal of A pplied Psychology, v. 53, n. 2, Pt. 1, p. 159-63, 1969; DIEHL e STROEBE, 1987; HARARI, 0. e GRAHAM, W. $K$. Tasks and task consequences as factors in individual and group brainstorming. Journal of Social Psychology, v. 95, n. 1, p. 61-5, 1975.

23. 0 bloqueio à produção refere-se à dificuldade de falar e de processar informação ao mesmo tempo, bem como à dificuldade de muitas pessoas competirem pela vez de falar. DIEHL e STROEBE (1987) oferecem um exame exato do bloqueio à produção. Ver também: DIEHL,
M. eSTROEBE, W. Productivity loss in idea-generating groups: tracking down the blocking effect. Journal of Personality and Social Psychology, v. 61 , n. 3, p. 392-403, 1991; STROEBE, W. e DIEHL, M. Why are groups less effective than their members? On productivity losses in idea generating groups. European Review of Social Psychology, n. 5, p. 271301, 1994.

24. Essa observação foi partilhada por executivos de alto nível na empresa.

25. Ver CAMACHO e PAULUS (1995); PAULUS e DZINDOLET (1993).

26. Ver SHEPPERD (1993).

27. Ver CAMACHO e PAULUS (1995); PAULUS e DZINDOLET (1993).

28. Ver STROEBE, W., DIEHL, M. e ABAKOUMKIN, G. The illusion of group effectivity. Personality and Social Psychology Bulletin, v. 18, n. 5, p. 643-50, 1992.

29. Ver JACKSON, S. E. Team composition in organizational settings: issues in managing an increasingly diverse work force. In: Worchel, S., Wood, W. eSimpson, J. A. (Eds.). Group process and productivity. Newbury Park : Sage, 1992. p. 138-73.

30. Ver DUNBAR, K. How scientists think: online creativity and conceptual change in science. In: Ward, T. B., Smith, S. M. e Vaid, J. (Eds.). Creative thought: an investigation of conceptual structures and processes. Washington : American Psychological Association, 1997. p. 461-93.

31. Ver GENTNER, D., BREM, S., FERGUSON, R. e WOLFF, P. Analogy and creativity in the works of Johannes Kepler. In: Ward, T. B. e Smith, S. M. (Eds.). Creative thought: an investigation of conceptual structures and processes. Washington : American Psychological Association, 1997. p. 403-59.

32. Esse exemplo, usado experimentalmente pela primeira vez por Gick e Holyoak em 1980, aponta para o vergonhoso problema concernente à inabilidade geral das pessoas para transferirem o conhecimento aprendido de um domínio a outro.

33. Ver THOMPSON, L., LOEWENSTEIN, J. e GENTNER, D. Avoiding missed opportunities in managerial life: analogical training more powerful than individual case training. Organizational Behavior and Human Decision Processes, v. 82, n. 1, p. 60-75, 2000. Esse artigo fornece dados de executivos indicando que 0 raciocínio analógico é mais poderoso do que 0 simples método de caso. O utro artigo desses autores fornece nosso modo de ver como os executivos devem ser ensinados: LOEWENSTEIN, J. e THOMPSON, L. The challenge of learning. N egotiation Journal, p. 399408, Oct. 2000.

34. Ver COX, A. Where there's muck there's brass: can a few days on the farm really improve your performance at work? The Guardian, London, 2 Aug. 2000.

35. Ver JAFFE, A. Chamber gleans words of wisdom from novel's plot. The Sunday Patriot N ews, Harrisburg, D01, N ov. 2000.

36. Ver HIGGINS (1994).

37. Id. Ibid. 
38. VerTHE human touch. The Economic Times. 7 N ov. 2000.

39. Ver RADCLIFF, D. Marriott: want to see the benefits of IT and business alignment? ComputerWorld, p. 58, 10 April 2000.

40. Ver LEE, T. Get those creative juices flowing. Business Plus section. St. Louis Post-Dispatch, 8B, 7 Jan. 2002.

41. Brainswriting provou ser uma técnica para real çar a performance de grupos reais. Para investigações diretas e empíricas, ver: GESCHKA, H., SCHAUDE, G. R. e SCHLICKSUPP, H. Modern techniques for solving problems. Chemical Engineering, p. 91-7, Aug. 1973; PAULUS, P. B. e YANG, H. Idea generation in groups: a basis for creativity in organizations. Organizational Behavior and Human Decision Processes, v. 82 , n. 1, p. $76-87,2000$.

42. Ver PAULUS e YANG (2000).

43. Ver HORN, E. M. The influence of modality order and break period on a brainstorming task. 1993. Honors thesis - University of Texas at Arlington.

44. VAN DE VEN, A. H. e DELBECQ, A. L. The effectiveness of nominal, Delphi, and interacting group decision making processes. Academy of Management Journal, v. 17, n. 4, p. 605-21, 1974.

45. Para uma clara demonstração de como a TGN é mais eficiente do que o brainstorming tradicional, ver: GUSTAFSON, D. H., SHUKLA, R., DELBECQ, A. e WALSTER, W. A comparative study in subjective likelihood estimates made by individuals, interacting groups, Delphi groups, and nominal groups. Organizational Behavior and Human Performance, v. 9, n. 2, p. 280-91, 1973.

46. Ver MULLEN, JOHNSON e SALAS (1991).

47. Ver WAH, L. Making knowledge stick. Management Review, p. 249, 1 May 1999.

48. Id. Ibid.

49. Facilitadores preparados são capazes de enquadrar muitos dos processos de problema de perda encontrados pelos grupos de brainstorming. Para estudos que examinam empiricamente a efetividade dos facilitadores preparados, ver: OFFNER, A. K., KRAMER, T. J. e WINTER, J. P. The effects of facilitation, recording, and pauses on group brainstorming.-Small Group Research, v. 27, n. 2, p. 283-98, 1996; OXLEY, N. L., DZIN DOLET, M. T. e PAULUS, P. B. The effects of facilitators on the performance of brainstorming groups. Journal of Social Behavior and Personality, v. 11, n. 4, p. 633-46, 1996.

50. Ver PAULUS, P. B., PUTMAN, V. L., COSKUN, H., LEGGETT, K. L. e RO LAND, E. J. Training groups for effective brainstorming. Trabalho apresentado na Quarta Conferência Anual de Conceitos Avançados em Equipes de Trabalho - Sessão de Implementação de Equipes. Dallas, 1996.

51. Ver SETA, J. J. The impact of comparison processes on coactors' task performance. Journal of Personality and Social Psychology, v. 42, n. 2, p. 281-91, 1982.

\section{Ver PAULUS e DZINDOLET (1993).}

53. Ver PAULUS, P. B., LAREY, T. S., PUTMAN, V. L., LEGGETT, K. L. eROLAND, E. J. Social influence processes in computer brainstorming. Basic and Applied Social Psychology, v. 18, n. 1, p. 3-14, 1996.

54. Ver SHEPHERD, M. M., BRIGGS, R. O., REINIG, B. A., YEN, J. e NUNAMAKER JR., J. F. Invoking social comparison to improve electronic brainstorming: beyond anonymity. Journal of $M$ anagement Information Systems, v. 12, n. 3, p. 155-70, 1995 /1996.

55. Ver ROY, M. C., GAUVIN, S. e LIMAYEM, M. Electronic group brainstorming: the role of feedback on productivity. Small Group Research, v. 27, n. 2, p. 215-47, 1996.

56. Isso é baseado em pesquisa minha e de Hoon-Seok Choi, conduzida no ano passado. Um paper que apresenta nossa pesquisa pode ser obtido de mim mesma ou do Professor Hoon-Seok Choi, Management $\&$ Organizations Department, Kellogg School of Management, Northwestern University, Evanston, IL 60208.

57. Ver SUTTON, R. L. e LOUIS, M. R. How selecting and socializing newcomers influences insiders. Human Resource Management, v. 26, n. 3, p. 347-61, 1987.

58. Ver ZILLER, R. C. Toward a theory of open and closed groups. Psychological Bulletin, v. 64, n. 3, p. 164-82, 1965.

59. Ver ROGELBERG, S. G., BARNES-FARRELL, J. L. e LOWE, C. A. The stepladder technique: an alternative group structure facilitating effective group decision making. Journal of Applied Psychology, v. 77, n. 5, p. 730-7, 1992.

60. Ver ROGELBERG, S. G. e O'CONNOR, M. S. Extending the stepladder technique: an examination of self-paced stepladder groups. Group Dynamics: Theory, Research, and Practice, v. 2, n. 2, p. 82-91.

61. Ver GROSSMANN, J. We've got to start meeting like this. Inc., 1 April 1998.

62. Ver LONG, S. This CEO handles complaints himself. The Straits Times, 12 April 2002.

63. Ver P.R. N ewswire. Surfboards in the boardroom and bocce ball out back. 25 Sept. 2001.

64. Ver LEE (2002).

65. Para uma extensa análise dos efeitos do afeto positivo sobre a criatividade, ver: ISEN, A. M., DAUBMAN, K. A. e NOWICKI, G. P. Positive affect facilitates creative problem solving. Journal of Personality and Social Psychology, v. 52, n. 6, p. 1122-31, 1987.

Para dar uma olhada no modo como a empresa Prada está repensando a criatividade, ver: BROWN, J. Prada gets personal. Business Week, EB8, 18 March 2002. Para uma análise de como a British Pretoleum está procurando petróleo no mar, ver: VERRENGIA, J. B. Finding footprints under Arctic ice. Associated Press, 8 Abril de 2002, via www.msnbc.com 